\title{
LOS CONFINES DEL DERECHO FUNDAMENTAL A LA VIDA'
}

\section{The confines of the fundamental right to life}

\author{
GONZALO ARRUEGO \\ Universidad de Zaragoza \\ garruego@unizar.es
}

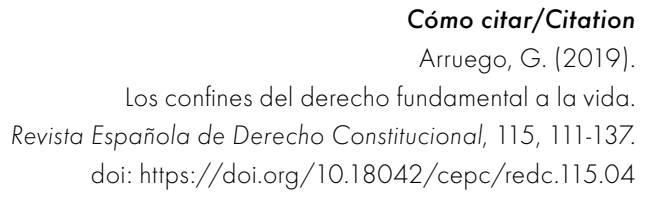

\section{Resumen}

A partir de la delimitación del objeto y contenido del derecho fundamental a la vida tal y como está consagrado en nuestro entorno constitucional, este estudio examina las tensiones a las que ciertas demandas lo someten y sus posibilidades de acomodo en el mismo. El trabajo analiza principalmente las relaciones entre el derecho a la vida y un hipotético derecho a disponer de la vida propia, especialmente con ayuda de terceros.

1 El presente estudio forma parte del proyecto nacional de investigación FRONTIUSFUND (DER2014-52817-P) y fue también posible gracias al proyecto PR201500334, desarrollado en el Sheffield Institute of Biotechnology, Law and Ethics. Expreso mi sincero y profundo agradecimiento al profesor Ricardo Chueca por sus atinadas observaciones a las distintas versiones de este trabajo, que versa sobre un tema acerca del que tantas horas de conversación hemos compartido. Quiero dar las gracias también a los evaluadores anónimos que revisaron este artículo, cuyas acertadas sugerencias y recomendaciones han redundado sin duda en su mejora.

La jurisprudencia del Tribunal Constitucional se cita indicando STC número de la sentencia/año de la sentencia/fundamento jurídico. 


\title{
Palabras clave
}

Derecho fundamental a la vida; consagración del derecho fundamental a la vida; objeto y contenido del derecho fundamental a la vida; libre disposición de la vida propia; muerte asistida.

\begin{abstract}
Departing from the analysis of the object and content of the fundamental right to life as it is currently consecrated, this study aims at exploring whether the fundamental right to life can accommodate certain demands. Within this framework, it focuses on the relationship between the fundamental right to life and the eventual recognition of a right to die and, more specifically, to assisted death.
\end{abstract}

\section{Keywords}

Fundamental right to life; proclamation of the fundamental right to life; object and content of the fundamental right to life; right to take one's own life; assisted death. 
I. INTRODUCCIÓN. II. UN CATÁLOGO DE DIFICULTADES. III. LA CONSAGRACIÓN DEL DERECHO FUNDAMENTAL A LA VIDA. IV. EL SIGNIFICADO DEL DERECHO FUNDAMENTAL A LA VIDA: 1. El derecho fundamental a la vida como garantía. 2. La problemática vis expansiva del deber estatal de protección. V. DERECHO A LA VIDA Y DERECHO A DISPONER DE LA VIDA PROPIA. VI. REFLEXIONES FINALES; REFERENCIAS. BIBLIOGRAFIA.

\section{INTRODUCCIÓN}

Aunque resulte paradójico dada la trascendencia que tradicionalmente se le atribuye, el derecho fundamental a la vida puede considerarse un «recién llegado». En comparación con otros derechos que poseen un largo recorrido histórico, su recepción en los textos constitucionales y en los instrumentos internacionales de protección de los derechos humanos se produjo tardíamente y como consecuencia de un acontecimiento que, probablemente además, ha marcado desde entonces sus posibilidades: la Segunda Guerra Mundial.

Quizá por ello, el derecho nació ya sometido a ciertas tensiones que ponen a prueba el sentido con el que fue proclamado ${ }^{2}$. Hoy, setenta años después, esas tensiones se han incrementado sensiblemente como consecuencia, entre otros factores, de las características de su objeto.

Así, junto con la sofisticación del debate sobre «tópicos» tradicionales como la protección debida a la vida humana en formación o la muerte asistida, afloran nuevos problemas; o quizá no tanto, pues en el fondo se trataría de cuestiones latentes que, derivadas de ciertas peculiaridades del derecho, solo precisaban de catalizadores que las pusieran de manifiesto.

Algunos de esos dilemas, especialmente el que postula que el derecho a la vida debe amparar el derecho a disponer de la vida propia, son objeto de este estudio.

El objetivo es dilucidar si el derecho fundamental puede efectivamente acomodar esta capacidad o si, por el contrario, lo desborda. En este último caso, y salvo que se adopte una postura de rechazo, no cabrían más opciones

2 Por ejemplo, y por lo que respecta al debate sobre la muerte asistida, un reciente examen de los movimientos "proeutanasia» ya desde la década de los setenta del siglo pasado en Indabas et al., 2017. 
que buscarle un encaje constitucional alternativo o, de fracasar, declarar que afrontamos un escenario que quizá reclame una regulación nueva.

Las siguientes páginas se abren con la ineludible exposición de algunas de las dificultades que afronta el estudio del derecho fundamental a la vida. Posteriormente se analiza su tratamiento en textos internacionales y constitucionales de referencia para extraer determinadas claves que ayudan a comprender su significado. A continuación, se examinan su objeto y su contenido y se alerta sobre los peligros de cierta dinámica interpretativa de su vertiente positiva o de protección. Finalmente, y a la luz de las conclusiones alcanzadas, se aborda cuál es la relación que existe entre el derecho y una hipotética facultad a disponer de la vida propia, especialmente con la ayuda de terceros.

\section{UN CATÁLOGO DE DIFICULTADES}

El análisis del derecho fundamental a la vida afronta un problema de partida quizá irresoluble: definir la vida humana como objeto del derecho. Esta cuestión trasciende la tradicional dicotomía entre una concepción puramente biológica de lo que garantiza y otra que incorpora elementos cualitativos e incluso subjetivos. En ambos casos, y aunque es cierto que con distinto alcance, los interrogantes acerca de qué es la vida humana, cuándo comienza y cuándo termina son ineludibles.

En otras palabras, ni siquiera sabemos a ciencia cierta qué protege exactamente el derecho. Un problema agravado además por la dependencia del estado del conocimiento científico-tecnológico y su creciente incidencia en los procesos jurídicos ${ }^{3}$. Y ello a pesar de que, evidentemente, el derecho solo puede proponer respuestas jurídicas y no científico-técnicas ${ }^{4}$.

3 Constatación a la que ni siquiera son ajenos los órganos jurisdiccionales de garantía de los derechos fundamentales; por ejemplo STEDH Goodwin c. Reino Unido (2002). Incluso hay quienes no dudan en afirmar que los cambios significativos en las ciencias de la vida y en la tecnología, y muy especialmente las transformaciones revolucionarias en nuestra concepción de qué es la vida, alumbran momentos «bioconstitucionales». Ello es consecuencia de que conmocionan hasta tal extremo los pilares de nuestras estructuras sociopolíticas que exigen un replanteamiento del sistema jurídico a nivel constitucional (Jasanoff, 2011: 3).

4 Ya en la década de los setenta del pasado siglo Glover alertaba del error de confundir los criterios establecidos a efectos sociales y legales con los propios de la realidad biológica (Glover, 1977: 127). 
Por ejemplo, respecto al grado de protección debido al ser humano en formación, los avances en neonatología determinan desde cuándo es capaz de sobrevivir fuera del vientre materno ${ }^{5}$. O, por lo que respecta al final de la garantía del derecho a la vida, el ordenamiento afronta la determinación del momento de la muerte desde la incertidumbre científica ${ }^{6}$. Así, la adopción de un criterio clínico u otro conlleva que desde el punto de vista jurídico un ser humano pueda considerarse al mismo tiempo vivo y no; o que el fallecido ya no lo sea y viceversa ${ }^{7}$.

Y todo ello sin olvidar la trascendencia de los factores sociales, económicos, culturales y valorativos, así como sus cambios; modificaciones ocasionalmente incoadas por transformaciones en el paradigma científico o por avances tecnológicos.

Situaciones que hasta hace unos años se incardinaban en un escenario de "contexto eutanásico ${ }^{8}$ " hoy son prácticas médicas protocolizadas en la lex artis y, en ciertos casos, expresión del ejercicio de derechos fundamentales ${ }^{9}$. La dis-

5 Recuérdese que, de forma similar a otras jurisdicciones, el TC adoptó en la STC 53/1985/5 un criterio gradual de protección de la vida humana en formación con arreglo al cual, y desde la perspectiva jurídico-constitucional, «tiene particular relevancia el nacimiento [...]. Y previamente al nacimiento tiene especial trascendencia el momento a partir del cual el nasciturus es ya susceptible de vida independiente de la madre, esto es, de adquirir plena individualidad humana».

6 En torno a las dificultades del concepto de muerte, puede consultarse, entre otros muchos, el monográfico Brain Death, American Journal of Bioethics, 8, 2014. Como expone Wicks, ante la evidencia de que el fallecimiento del organismo es un proceso, se ha cuestionado la corrección de establecer jurídicamente una línea cierta que separe la vida y la muerte; desde este punto de vista, lo pertinente es responder a cuestiones como cuándo es legítimo retirar medidas de soporte vital, cuándo se pueden extraer los órganos para su trasplante o cuándo puede enterrarse o cremarse un cuerpo (Wicks, 2010: 12-13). En el debate en torno a los distintos criterios para determinar el óbito no han faltado propuestas para que sea el propio individuo quien elija con arreglo a qué parámetros se certificará su defunción, por ejemplo, Veatch, 1999.

7 Por ejemplo, Summer, 2011; como muy ilustrativamente afirmó Skegg para referirse a lo contraintuitivo de algunas situaciones: «A beating heart cadaver» (Skegg, 1988: 520).

8 Terminología expresamente rechazada por el legislador de las decisiones sobre el final de la vida; sobre estas cuestiones vid., entre otros, Simón et al., 2008, y Beltrán, 2010.

9 Así, el rechazo de un tratamiento médico de soporte vital como expresión del derecho fundamental a la integridad personal. Una cuestión sobre la que, sin embargo, el TEDH opina que no existe acuerdo total entre los países del Consejo de Europa 
cusión en torno a la muerte asistida es históricamente reciente y se ha hecho más presente en las sociedades ricas y avanzadas ${ }^{10}$, donde morir es un proceso medicalizado que además se torna estatal allí donde existen sistemas públicos de salud (Chueca, 2017). El rol del personal sanitario se transforma por su participación en procesos cuya naturaleza no es ni terapéutica ni paliativa ${ }^{11} y$ como consecuencia del creciente peso que el ordenamiento otorga a su opinión en las decisiones al final de la vida ${ }^{12}$.

En suma, una tupida red de factores sociales, culturales, económicos, científicos y tecnológicos concurre inevitablemente en el análisis del derecho fundamental a la vida. Obviamente, abordar estos problemas excede el objeto de estas páginas, pero no perderlos de vista es imprescindible para comprender algunas de las incógnitas que en sede jurídico-constitucional suscita el derecho.

\section{LA CONSAGRACIÓN DEL DERECHO FUNDAMENTAL A LA VIDA}

La incorporación del derecho a la vida como derecho fundamental autónomo en los documentos internacionales de protección de los derechos humanos y en los textos constitucionales es relativamente reciente ${ }^{13}$.

(SSTEDH Lambert y otros c. Francia [2015] \$\$ 147 y 148, y, más recientemente, Afiri y Biddarri c. Francia [Sección 5.; 2018], \$28).

10 Como explica Pabst, el debate público y doctrinal sobre la muerte asistida se generaliza a finales del siglo xx y principios del xxI en las sociedades desarrolladas, sobre todo como consecuencia de tres cambios. El primero, en las causas por las que fallecemos: de la muerte provocada por enfermedades parasitarias e infecciosas al deceso en edades avanzadas por afecciones degenerativas («transición epidemiológica»). El segundo, en la actitud religiosa hacia la muerte. El tercero, en la construcción de las relaciones médico-asistenciales a partir del principio de autonomía individual (Pabst, 2005).

11 Vid., por ejemplo, Prokopetz y Soleymani, 2012.

12 En el caso de aquellas jurisdicciones que han legalizado bajo ciertas condiciones la muerte asistida, McLean habla de la conversión del personal médico en auténtico gatekeeper (McLean, 2007: 198).

13 Así, y por citar algunas de las referencias clásicas en materia de derechos fundamentales, el derecho no aparece como tal ni en la Carta Magna (1215), ni en el Bill of Rights (1869), ni en la Declaración de derechos del hombre y del ciudadano (1789), pero sí en el Bill of Rights de EE. UU. de 1791: la 5. a enmienda a la Constitución establece que «nadie será privado de la vida [...] sin el debido proceso legal». Ya la primera parte del segundo párrafo de la Declaración de Independencia (1776) afirmaba: 
Comenzando por los primeros, la parquedad del art. 3 de la Declaración Universal de Derechos Humanos y del art. 2 de la Carta de los derechos fundamentales de la Unión Europea, que se limitan a afirmar que toda persona «tiene derecho a la vida ${ }^{14}{ }^{4}$, contrasta con el tenor de los arts. 6 del Pacto Internacional de Derechos Civiles y Políticos, 4 de la Convención Americana sobre Derechos Humanos y 2 del Convenio Europeo de Derechos Humanos. De los tres se desprendería que el derecho es, principalmente, una prohibición.

Tras proclamar que es inherente a la persona y garantizar su protección por la ley, el art. 6 del Pacto parece explicitar que el contenido primario del derecho a la vida consiste en la interdicción de privar «arbitrariamente» de la existencia física ${ }^{15}$. También el art. 4 de la Convención, que contiene previsiones similares pero introduce un importante matiz: «en general», la vida humana se protege desde «el momento de la concepción ${ }^{16} »$.

«Sostenemos que estas verdades son evidentes en sí mismas: que todos los hombres son creados iguales; que están dotados por su Creador de ciertos derechos inalienables; que entre éstos están la vida, la libertad y la búsqueda de la felicidad»; una redacción que difiere de la contenida en su rough draft, que hablaba del derecho a la "preservación de la vida" y que, tal y como se mostrará infra, resulta muy expresiva del contenido nuclear que tradicionalmente se atribuye al derecho y con el que probablemente fue concebido.

14 La Declaración establece: «Todo individuo tiene derecho a la vida, a la libertad y a la seguridad de su persona»; por su parte, el art. 2 de la Carta, ubicado en su capítulo I, bajo la rúbrica "Dignidad», afirma: "Toda persona tiene derecho a la vida», y excluye absolutamente en su segundo párrafo que cualquier individuo sea condenado a muerte o ejecutado.

15 Art. 6.1: «El derecho a la vida es inherente a la persona humana. Este derecho estará protegido por la ley. Nadie podrá ser privado de la vida arbitrariamente». El resto del precepto establece una serie de restricciones y garantías relativas a la pena capital: que solo puede circunscribirse a los delitos más graves tras el oportuno proceso, que no cabe su imposición a menores de 18 años ni su aplicación a mujeres embarazadas y que el condenado tendrá derecho a solicitar el indulto o conmutación de la pena, que podrán concederse en todos los casos.

16 Art. 4.1: «Toda persona tiene derecho a que se respete su vida. Este derecho estará protegido por la ley y, en general, a partir del momento de la concepción. Nadie puede ser privado de la vida arbitrariamente». En opinión de la Comisión Interamericana de Derechos Humanos (Resolución n. 23/81, Caso 2141 [1981], especialmente $₫ 19$ ), el modo en que se hizo referencia a la protección de la vida prenatal tuvo como finalidad rechazar la extensión del derecho a la vida desde el momento de la concepción, pues habría hecho incompatible la Convención con la diversidad legislativa en materia de aborto. Posteriormente, la Corte Interamericana de Derechos Humanos ha afirmado que «el embrión no puede ser entendido 
Finalmente, y junto con las prescripciones relativas a la pena capital, el art. $2 \mathrm{CEDH}$ declara que «el derecho de toda persona a la vida está protegido por la ley» y prohíbe arrebatar intencionadamente la vida. Su párrafo segundo establece un catálogo de circunstancias en las que es lícito recurrir al uso de la violencia ocasionando involuntariamente la muerte. Es decir, no son situaciones en las que es legítimo matar deliberadamente ${ }^{17}$.

Salvo las excepciones anteriormente reseñadas, la recepción constitucional del derecho fundamental a la vida también es un fenómeno reciente pero no generalizado. Y, de nuevo, el lenguaje escogido es elocuente en la interpretación dominante de su naturaleza y contenido.

En el ámbito de la Unión Europea pueden distinguirse tres situaciones. En primer lugar, los textos constitucionales que se han limitado a abolir la pena capital sin incluir mención alguna al derecho fundamental a la vida ${ }^{18}$.

como persona para efectos del artículo 4.1 de la Convención Americana. Asimismo, [...] la "concepción" en el sentido del artículo 4.1 tiene lugar desde el momento en que el embrión se implanta en el útero, razón por la cual antes de este evento no habría lugar a la aplicación del artículo 4 de la Convención. Además, es posible concluir de las palabras "en general" que la protección del derecho a la vida con arreglo a dicha disposición no es absoluta, sino es gradual e incremental según su desarrollo, debido a que no constituye un deber absoluto e incondicional, sino que implica entender la procedencia de excepciones a la regla general» (Artavia Murillo y otros c. Costa Rica [2012], \$ 264).

17 STEDH McCann y otros c. Reino Unido (1995), $\$ 148$. Básicamente, cuando el fallecimiento es consecuencia del necesario uso de la fuerza en defensa de una persona frente a una agresión ilegítima, para detener conforme a derecho a una persona o evitar la evasión de un preso o detenido legalmente, o para reprimir dentro de la legalidad una revuelta o insurrección. No pueden olvidarse el Protocolo n. 6 al Convenio Europeo para la Protección de los Derechos Humanos y de las Libertades Fundamentales relativo a la abolición de la pena de muerte (1983) y el Protocolo n. 13 al Convenio Europeo para la Protección de los Derechos Humanos y de las Libertades Fundamentales relativo a la abolición de la pena de muerte en cualquier circunstancia (2002).

18 Por ejemplo, constituciones de Bélgica, Holanda, Italia, Luxemburgo o Suecia. Es cierto que la Constitución belga garantiza en su art. 23 el derecho a «llevar una vida conforme con la dignidad humana». Sin embargo, su contenido se cifra en una serie de derechos «económicos, sociales y culturales» cuyas condiciones de ejercicio corresponde determinar a la ley. En particular, abarca cuestiones relativas al empleo, a la protección de la salud y a la seguridad social, a la vivienda, al medioambiente y a la cultura. Por lo que respecta al peculiar caso de Reino Unido y al recurso al derecho fundamental a la vida por su más alta instancia judicial, se ha afirmado que de su labor parece desprenderse cierta renuencia a hacer una lectura del common law 
Un segundo grupo formado por aquellos que expresamente se refieren a la protección de la vida humana pero que lo hacen en forma de garantía o imposición al poder público de un deber de protección ${ }^{19}$. Por último, aquellos ordenamientos que utilizan el término "derecho ${ }^{20}$ ", si bien no son pocos los casos en los que la explicitación del significado del «derecho a la vida» desemboca en un contenido próximo al grupo anterior ${ }^{21}$.

En suma, el momento y el lenguaje utilizado en la proclamación internacional y constitucional del derecho fundamental a la vida sugieren, cuando no

británico a partir del concepto de derecho a la vida; por el contrario, se habrían mantenido las categorías legales tradicionales dejando que sea el Tribunal Europeo de Derechos Humanos el que asuma el liderazgo en su construcción (Dickson, 2013: 101).

19 Por ejemplo, constituciones eslovena, griega, irlandesa, polaca o portuguesa, pues aunque el epígrafe de su art. 24 reza "derecho a la vida», su enunciado garantiza la «inviolabilidad» de la vida humana. La Constitución de Irlanda posee en estas cuestiones una historia peculiar consecuencia de la protección constitucional dispensada históricamente al no nacido. Su último capítulo tuvo lugar en diciembre de 2018 con la legalización del aborto mediante la Health (Regulation of Termination of Pregnancy) Act 2018, tras la reforma del artículo 40.3.3 de la Constitución aprobada el 26 mayo del mismo año en un histórico referéndum. Dicho precepto, introducido en el año 1983, sí utilizaba el término «derecho» cuando reconocía «el derecho a la vida del no nacido" y afirmaba el compromiso de la ley en su garantía y, hasta donde fuera posible, su defensa "con la debida consideración al igual derecho de la madre a la vida" [véase la sentencia del Tribunal Supremo de Irlanda My otros c. Ministro de Justicia e Igualdad (2018) que, entre otras cuestiones, concluyó que el no nacido no poseía más derechos constitucionales que el garantizado por el art. 40.3.3 de la Constitución]. Actualmente, el precepto se limita a habilitar al legislador para «regular la terminación del embarazo». En este contexto, la Constitución de Eslovaquia, en su art. 15.1, o la Carta de Derechos y Libertades Fundamentales de la República Checa, art. 6.1, consagran la protección de la vida humana antes del nacimiento.

Además de la Constitución española, las constituciones alemana, búlgara, chipriota, eslovaca, estonia, finesa, letona, lituana, maltesa, rumana o la Carta de derechos y libertades fundamentales de la República Checa. En el caso español, véase además la Ley Orgánica 11/1995, de 27 de noviembre, de abolición de la pena de muerte en tiempo de guerra.

21 Por ejemplo, los arts. 6 de la Carta de derechos y libertades fundamentales de la República Checa, 7 de la Constitución de Chipre, 15 de la Constitución de Eslovaquia, 16 de la Constitución de Estonia, la sección 7 de la Constitución de Finlandia o el art. 33 de la Constitución de Malta, explican que el derecho a la vida es una garantía que protege frente a su privación arbitraria o fuera de las circunstancias establecidas por el ordenamiento jurídico. 
evidencian, que lo comúnmente garantizado es, sobre todo, la prohibición de privar arbitrariamente de la existencia ajena ${ }^{22}$.

Ello dilucida el aparente contrasentido de que su proclamación incorpore a veces previsiones sobre la pena capital: en última instancia se trata de asegurar cuándo el poder público está legitimado para privar de la vida a las personas sujetas a su jurisdicción. Unas circunstancias muy limitadas en el ámbito del Consejo de Europa gracias a los protocolos 6 y 13 al Convenio Europeo de Derechos Humanos ${ }^{23}$.

\section{EL SIGNIFICADO DEL DERECHO FUNDAMENTAL A LA VIDA}

\section{EL DERECHO FUNDAMENTAL A LA VIDA COMO GARANTÍA}

Tal y como se afirmó supra, el primer problema que suscita el examen del derecho fundamental a la vida es definir su objeto.

Obviamente, ningún texto normativo precisa qué es la vida humana, de modo que los órganos jurisdiccionales se han visto forzados a ir acotando tan problemático concepto, aunque solo a los efectos de lo exigido por sus sucesivos pronunciamientos ${ }^{24}$.

Parece que hoy en día predomina una interpretación estrictamente «existencial» del derecho como garante de la vida humana como realidad biológica. Ello es patente en las doctrinas del TC y del TEDH; también, por ejemplo, en la del Tribunal Supremo de Canadá25.

22 Distinto es que no faltan quienes cuestionan que siga siendo adecuado mantener esta configuración del derecho; en este sentido, McLean, 2007: 16.

23 Como explica Wicks, ambos protocolos no son consecuencia del derecho fundamental a la vida sino resultado de un acto de autolimitación de soberanía estatal (Wicks, 2010: 105); no faltan sin embargo quienes sostienen que esta situación es «contradictoria e incompatible» con el derecho (Schabas, 2002: 7).

24 En el ámbito del CEDH, Korff explica que ante la indefinición del art. 2 CEDH y la falta de consenso legal y científico, primero la Comisión y actualmente el TEDH han sido reacios a establecer criterios precisos en estas materias, decidiendo, por ejemplo, sobre cuestiones relativas al principio de la vida "solo de manera marginal y caso a caso" (Korff, 2006: 8-9 y 13).

25 No es así exactamente en el caso de la Corte Constitucional colombiana, el primer órgano jurisdiccional que afirmó que de su texto constitucional se derivaba un «derecho fundamental a la muerte digna» (Sentencia C-239/97). Sin embargo, la incorporación en su jurisprudencia de elementos vinculados al concepto de "vida digna» no ha alterado la interpretación del derecho como una "garantía» en los términos que a 
En opinión del Tribunal Constitucional, la vida humana es un «devenir» o "proceso" que comienza con la gestación y que finaliza con la muerte. Ambos momentos delimitarían, sin que el Tribunal precise más acerca de su significado, el comienzo y el final de una garantía constitucional que posee un carácter "gradualista ${ }^{26}$ ». Como expresamente afirma el TEDH, los juicios o valoraciones que la persona pudiera realizar acerca de su vida son ajenos al derecho y habrían de encontrar, en su caso, acomodo en otras posiciones iusfundamentales ${ }^{27}$. Una tesis sostenida en términos similares por el Tribunal Supremo de Canadá, que expresamente califica esta interpretación como "concepción existencial del derecho a la vida ${ }^{28}$ ".

El contenido del derecho estaría así encaminado a proteger la existencia física de sus titulares frente a agresiones y amenazas también interpretadas en sentido estricto ${ }^{29}$. En otras palabras, como la existencia es un hecho natural, el derecho solo es inteligible en términos negativos como garantía frente a su privación fuera de las condiciones normativamente establecidas y como deber de su protección ${ }^{30}$.

continuación se describen, sino que ha servido para enriquecer esa concepción existencial.

26 STC 53/1985/5. De ahí que, por ejemplo, tanto el material reproductivo humano como el cuerpo de la persona fallecida sean ajenos al art. 15 CE (STC 116/1999/7 y ATC 149/1999/2, reiterado por la STC 3/2005/8, respectivamente). Por otro lado, y con relación a los estadios del proceso vital previos al nacimiento, el art. $15 \mathrm{CE}$ protegería en grado no uniforme solo la vida humana en formación biológicamente viable (STC 212/1996/5).

27 STEDH Pretty c. Reino Unido (2002), $\$ 39$. Dichas consideraciones se reconducirían al derecho a la vida privada enunciado en el art. $8 \mathrm{CEDH}$.

28 «[...] de nuestra jurisprudencia se desprende que el derecho a la vida está comprometido cuando se causa la muerte o se incrementa su riesgo ya sea directa o indirectamente. Por el contrario, las consideraciones relativas a la autonomía individual o a la calidad de vida se han ubicado tradicionalmente en los derechos a la libertad y a la seguridad. No apreciamos razón alguna para modificar esta concepción [...] existencial del derecho a la vida» (Carter c. Canadá [Fiscal General] [2015], \$\$ 62 y 63).

29 Por eso, y por lo que respecta a la doctrina del Tribunal Constitucional, la denegación de una pensión de viudedad no guarda relación con el art. 15 CE (ATC 241/1985/2) o se ha distinguido cuidadosamente en el ámbito de las indemnizaciones por accidente de tráfico entre la «reparación del estricto daño personal», sí sujeto a sus exigencias, y «la restauración del equilibrio patrimonial perdido», ajeno al mismo (STC 181/2000/8).

30 Como afirma Zucca, el derecho fundamental a la vida es un «derecho negativo», pues su contenido es esencialmente una prohibición (Zucca, 2007: 149); por ello Rey lo 
Tal y como se ha mostrado, esta interpretación se corresponde con el lenguaje que mayoritariamente utilizan los textos constitucionales e internacionales para proclamarlo y explica por qué el TEDH no ha dudado en afirmar que el art. $2 \mathrm{CEDH}$ «es ante todo una prohibición ${ }^{31}$ \%.

Puede atribuirse así sentido a la reiterada interpretación de las decisiones de libre disposición de la vida propia como un (imposible) conflicto entre derechos del mismo titular. La hace inteligible porque el uso del término derecho con relación a la vida sería equívoco: no es tanto un derecho como garantía para el individuo y fuente de obligaciones para el Estado ${ }^{32}$. Pero la hace comprensible apenas parcialmente, pues solo de modo impropio puede hablarse de conflicto; en el fondo, lo que estaría en juego es determinar el alcance de los deberes que la protección de la vida impone al poder público.

Pero además, la constatación de que el derecho a la vida es fundamentalmente una interdicción hay que relacionarla con una de sus peculiaridades más características: por regla general, su violación comporta la desaparición física de su titular ${ }^{33}$.

Esta circunstancia conduce a una interesante paradoja: si no se hubiera interpretado que para apreciar su lesión no es preciso que se haya producido la muerte de la persona y si no se hubiera ensanchado progresivamente el contenido del deber de protección, el derecho a la vida carecería de facto de contenido

califica como «un derecho de defensa», prefiere hablar de «derecho a la protección jurídica de la vida» y entiende que la formulación del art. $2 \mathrm{CEDH}$ es más correcta técnicamente que la del art. 15 CE (Rey, 2008; 2009).

31 El art. 2 de la Convención «es ante todo una prohibición del uso letal de la fuerza y de cualquier otra conducta que pueda ocasionar la muerte de un ser humano. No confiere ningún derecho a requerir del Estado que permita o facilite la muerte propia» (STEDH Pretty c. Reino Unido [2002], \$ 54).

32 Por ejemplo, el Tribunal Constitucional no ha mostrado reparos en utilizar el derecho a la vida del recurrente en amparo para limitar sus derechos a la integridad física y moral o a la libertad ideológica. El caso de las SSTC 11 y 67/1991 es especialmente llamativo, pues se asiste a la interposición de sendos recursos de amparo por el Ministerio Fiscal para preservar el derecho a la vida de unos reclusos que se personan en el proceso defendiendo la actuación de los poderes públicos supuestamente lesiva. El TEDH afirma explícitamente que cuando «una persona privada de libertad se declara en huelga de hambre, se produce inevitablemente un conflicto entre su derecho a la integridad física y las obligaciones positivas que al Estado impone el artículo 2 del Convenio» (STEDH Nevmerzhitsky c. Ucrania [2005], \$ 93, entre otras).

33 El TEDH ha reiterado que la violación del derecho no tiene que estar necesariamente anudada al fallecimiento del individuo; asimismo, TEDH y TC han reconocido que el derecho protege frente a agresiones efectivas y situaciones de riesgo de lesión. 
subjetivo en sentido estricto. Nótese que como garantía frente a la privación de la existencia física el derecho posee un contenido estrictamente reaccional que consiste en recabar amparo frente a su violación ${ }^{34}$. Pero esta significará usualmente el deceso del individuo.

\section{LA PROBLEMÁTICA VIS EXPANSIVA DEL DEBER ESTATAL DE PROTECCIÓN}

Frente a la estrechez de su contenido desde un punto de vista subjetivo, desde la perspectiva del Estado el derecho a la vida posee, sin embargo, una dinámica claramente expansiva que dilata el espacio potencial de demanda de su titular. Como han reiterado TC y TEDH, el derecho no se agota en la prohibición de privación de la existencia, sino que impone al poder público un conjunto de obligaciones positivas encaminadas a protegerla ${ }^{35}$.

Tradicionalmente, los deberes que se han derivado de la garantía del derecho son coherentes con su contenido primero. Típicamente, los ordenamientos trasladan a las relaciones entre particulares la proscripción de privar de la vida ajena recurriendo a la disuasión y represión penales ${ }^{36}$, implementan normas o, incluso, y siempre dependiendo de cómo se interprete su alcance, adoptan

34 «El derecho fundamental a la vida, en cuanto derecho subjetivo, da a sus titulares la posibilidad de recabar el amparo judicial y, en último término, el de este Tribunal frente a toda actuación de los poderes públicos que amenace su vida [...]» (STC 120/1990/7).

35 «El derecho fundamental a la vida, en cuanto [...] fundamento objetivo del ordenamiento impone a esos mismos poderes públicos y en especial al legislador, el deber de adoptar las medidas necesarias para proteger esos bienes, vida e integridad física, frente a los ataques de terceros, sin contar para ello con la voluntad de sus titulares e incluso cuando ni siquiera quepa hablar, en rigor, de titulares de ese derecho» (ibid.).

36 Respecto de la protección penal constitucionalmente debida a la vida humana, el Tribunal Constitucional ha recordado que no puede revestir un carácter absoluto y que el competente para determinar su extensión es el legislador democrático con arreglo, sobre todo, al principio de mínima intervención (SSTC 212/1996/10 y 116/1999/16). Por ejemplo, el TEDH ha afirmado que el art. $2 \mathrm{CEDH}$ no impone sistemáticamente la represión penal para todo caso de violación involuntaria del derecho a la vida (SSTEDH Calvelli y Ciglio c. Italia [2002], $\$ 51$ o Vo c. Francia [2004], \$ 90). Un examen crítico de la evolución de la doctrina del TEDH acerca de la relación entre garantía del derecho a la vida y responsabilidad penal, alertando de su doble riesgo de extralimitación y debilitamiento del derecho, en Mavronicola, 2017. 
medidas preventivas para ordenar actividades potencialmente peligrosas para la vida humana y para proteger a personas en situación de riesgo ${ }^{37}$.

El dilema reside en interpretar ajustadamente el alcance de este deber estatal de "proteger la vida de todos los sujetos a su jurisdicción»; obligación expuesta a una problemática pendiente resbaladiza.

Efectivamente, es apreciable cierto ensanchamiento descontrolado de la dimensión positiva del derecho que incrementa sensiblemente el riesgo de hacer pasar como demandas iusfundamentales otras exigencias que, aunque legítimas, derivan en su caso de otros principios y valores constitucionales. Hay aquí un creciente peligro de trivializarlo o desnaturalizarlo al sobreinvolucrarlo e, incluso, convertirlo en irrealizable.

Esta dinámica quizá pueda explicarse parcialmente a la luz de algunos excesos en la caracterización que usualmente se hace del derecho fundamental a la vida.

La obviedad de que sin existencia no hay soporte individual de derechos ha sido impropiamente utilizada para atribuirle una posición única en el catálogo de derechos fundamentales con reflejo inmediato en su interpretación.

Por ejemplo, el Tribunal Constitucional ha reiterado que es el «derecho fundamental esencial y troncal», pues junto con la dignidad humana constituye el «prius lógico y ontológico» de todos los restantes ${ }^{38}$. Esta particularidad le otorgaría "una singular fuerza expansiva ${ }^{39}$ " e, incluso, y en un evidente exceso, un carácter «absoluto e ilimitable ${ }^{40}$ ». El TEDH ha alcanzado conclusiones similares atribuyendo "preeminencia» a un derecho que constituye una de las previsiones «más fundamentales del Convenio ${ }^{41}$ ».

37 En esta materia es clásica la cita de STEDH Osman c. Reino Unido (1998), especialmente $\$ \$ 115$ y 116 , relativa a la protección debida frente a los actos violentos de terceros; en relación con los deberes positivos de protección en el caso de una persona con impulsos suicidas custodiada por los poderes públicos, vid. STEDH Keenan $c$. Reino Unido (2001); respecto a una situación de riesgo generada por actividades industriales peligrosas, vid. STEDH Guerra y otros c. Italia (1998) y, sobre todo, STEDH Önerynldiz c. Turquí (2004). Una sistematización de los deberes positivos derivados del art. 2 CEDH, por ejemplo, en Korff, 2006, y Barcelona, 2007.

38 STC 53/1985/3, entre otras.

39 ATC 304/1996/3.

40 STC 48/1996/2.

41 Todo ello la luz «del principio de santidad de la vida humana» y de que sin la vida «el disfrute de los demás derechos y libertades» es imposible; entre otras, STEDH Pretty c. Reino Unido (2002), $\$ \$ 37$ y 65, ya citada. En sentido similar y en el ámbito de la Convención Interamericana de Derechos Humanos, Villagrán Morales y otros c. Guatemala (1999), \$ 144. 
En esta línea, no parece casual la conexión que habitualmente se establece entre derecho a la vida y dignidad de la persona ${ }^{42}$; tampoco que los problemas en la interpretación del deber de protección de la vida humana estén sobre todo aflorando en ciertas jurisdicciones, aunque sean también perceptibles en el ámbito del $\mathrm{CEDH}^{43}$.

La conexión vida/dignidad humana altera la comprensión del derecho a la vida como garante de la existencia física del individuo al incorporar factores que tienen que ver con sus condiciones de desenvolvimiento (medioambientales, sanitarias, alimentarias, etc.) e incluso con su percepción subjetiva; un cambio sutil pero que transforma sustancialmente el objeto y alcance del derecho y que puede desbordarlo hasta hacerlo irreconocible. Es cierto, no obstante, que muchos de esos contenidos son rastreables en preceptos constitucionales de diversa naturaleza. El problema radica en su correcta inserción en el sistema de derechos fundamentales.

En el extremo, es relativamente sencillo relacionar un determinado asunto con las circunstancias materiales y espirituales de la vida humana. De ahí a banalizar el derecho haciendo inviable su garantía y absolutamente dependiente de la disposición y recursos del poder público en cada momento hay un pequeño paso. Una suerte de «efecto globo» al que sería muy difícil poner freno ${ }^{44}$. Y todo ello, obviamente, sin negar el profundo calado de los problemas subyacentes ${ }^{45}$.

42 En torno a la conexión derecho fundamental a la vida y dignidad humana, vid., entre otros, Wicks, 2012; sobre el recurso al concepto dignidad de la persona en el debate sobre la muerte asistida, vid. Loveland, 2016, y Muders, 2017.

43 Por ejemplo, en el ámbito de la salud, vid. Toebes et al., 2012.

44 Como explica Griffin, «desde el mismo momento en que comienza a reflexionarse sobre los fundamentos del derecho a la vida, su contenido parece expandirse irresistiblemente trascendiendo la mera exclusión de privar de la existencia». Por ejemplo, «si vivir con libertad es valioso, el derecho no debería limitarse a la mera preservación de la vida, sino a garantizar que efectivamente se vive en libertad». Yendo más allá, progresivamente incorporaría deberes positivos "como alimentar al hambriento o suministrar asistencia sanitaria al enfermo». En definitiva, «¿garantizaría también el derecho a que la vida se desenvuelva en determinadas condiciones? Por ejemplo, ¿el acceso a agua potable y a la educación, por citar dos circunstancias que acortan drásticamente la esperanza de vida infantil?». En su opinión, «este efecto globo al que el contenido del derecho a la vida está sometido no es una mera posibilidad teórica, sino algo que ya está sucediendo» (Griffin, 2008: 212-213).

45 Ello es rastreable, por ejemplo, en la doctrina de la Corte Constitucional colombiana; vid. en el contexto de la muerte asistida la Sentencia T-322/17. 
Por ejemplo, ¿¿forma parte del contenido del derecho a la vida el acceso a medicamentos con potencial para salvarla o prolongarla ${ }^{46}$ ? $; Y$ disfrutar de aquellas condiciones que garanticen una existencia «digna ${ }^{47} »$ ? ¿Y cuáles son tales condiciones: nutrición, ropa, cobijo, educación ${ }^{48} \ldots$ ?

\section{DERECHO A LA VIDA Y DERECHO A DISPONER DE LA VIDA PROPIA}

Las páginas precedentes evidencian la dificultad de incardinar en el derecho fundamental a la vida facultades de libre disposición de la vida propia.

Al tratarse de un derecho negativo y de carácter reaccional que fundamentalmente impone al poder público una prohibición (no privar de la vida) y un conjunto de deberes positivos de protección (proteger la vida de aquellos sometidos a su jurisdicción), tal facultad subjetiva sobre su objeto le resulta extraña.

46 Por ejemplo, a medicamentos genéricos para combatir el virus del sida en Kenia frente a los derechos de propiedad intelectual esgrimidos por las multinacionales farmacéuticas, vid. Harrington, 2014; en el caso de acceso a fármacos experimentales, vid. SSTEDH Hristozov y otros c. Bulgaria (2012) y Gard y otros c. Reino Unido (Sección Primera; 2017). En agosto de 2006, el England's National Institute for Clinical Excellence (NICE) decidió no incorporar a la cartera de servicios del National Health Service (NHS) un tratamiento para el cáncer intestinal terminal porque su coste económico se consideró excesivo en relación con la perspectiva de prolongar cinco meses la vida de los enfermos, vid. Rose, 2010.

47 CIDDHH Villagrán Morales y otros c. Guatemala (1999), $\$ 144$, antecitada.

48 Por ejemplo, el Tribunal Supremo de la India, que recientemente ha reconocido la tradicionalmente denominada eutanasia pasiva en su sentencia Common Cause ( $A$ Regd. Society) c. Union of India y otro (2018), ha afirmado que el derecho a la vida incluye todos aquellos elementos anudados a una existencia digna; fundamentalmente la satisfacción de las necesidades básicas, como «nutrición, ropa y cobijo adecuados o los medios para poder leer, escribir o expresarse y relacionarse libremente con el resto de seres humanos» (Francis Coralie Mullin c. The Administrator, Union Territory of Delhi [1981]). Por ejemplo, para YORKE estos deberes positivos conllevan la obligación de "promover el derecho a la vida", de la que derivarían tareas como «reducir la mortalidad infantil»o «incrementar la esperanza de vida a través de un servicio de salud adecuado que cubra las necesidades de la población» (Yorke, 2010: 4); o, en relación con algunos de los contenidos de la DUDDHH, la inclusión de elementos propios de «derechos de segunda generación» en el derecho a la vida no sería sino expresión de la necesidad de trascender su carácter de mera prohibición «si se quiere reflejar genuinamente el valor que merece la vida humana» (Wicks, 2010: 40). 
Desde este punto de vista, el derecho muestra una inelasticidad que es consistente con el significado que reiteradamente se le atribuye desde sus primeras formulaciones. Repárese en un dato muy significativo: incluso aquellas jurisdicciones más receptivas a reconocer la legitimidad y legalidad de dichas capacidades rechazan ampararlas en el derecho fundamental a la vida ${ }^{49}$.

Ahora bien, esta afirmación en nada prejuzga la posibilidad de reconocerlas. Como explica el Tribunal Supremo de Canadá en Carter, este entendimiento del

49 Ni la Corte Constitucional de Colombia ni el Tribunal Supremo de Canadá, por citar los dos tribunales constitucionales que han reconocido la muerte asistida bajo ciertas condiciones, han modificado la interpretación del derecho fundamental a la vida como garantía. En el caso colombiano, se ha reconocido el «derecho fundamental a la muerte digna» como un derecho autónomo, de contenido complejo y poseedor de una clara vertiente prestacional, que otorga a su titular un conjunto de facultades para gestionar o gobernar los últimos momentos de su vida en el marco médico-asistencial y siempre que se cumplan determinadas condiciones. De entre esas facultades destaca muy en primer lugar la eutanasia, accesible solo a quienes padecen una enfermedad terminal que les provoca un intenso sufrimiento. También abarca la limitación del esfuerzo terapéutico y el acceso a los cuidados paliativos en el caso de enfermos terminales o que padecen una enfermedad crónica, degenerativa e irreversible "con alto impacto en su calidad de vida»; vid. sentencias T-970/14 y T-721/17, entre otras. Por su parte, el Tribunal Supremo de Canadá declaró en el año 2015 en Carter la inconstitucionalidad de la prohibición absoluta de la ayuda al suicidio por constituir una intromisión injustificada en los derechos fundamentales a la vida, a la libertad y a la seguridad. Y ello a pesar de que en Rodriguez c. Columbia Británica (Fiscal General) (1993) había sostenido, bien que por una exigua mayoría de cinco a cuatro, lo contrario. En ambas decisiones el planteamiento es similar: la prohibición absoluta de la muerte asistida constituye una interferencia en los derechos a la libertad y a la seguridad. En Rodriguez la conclusión fue que esa injerencia estaba justificada porque excepcionar tal proscripción podía frustrar el cumplimiento del deber de proteger la vida humana como consecuencia de la imposibilidad de adoptar mecanismos de control eficaces. Doce años más tarde, Carter concluye que, aunque es cierto que legalizar la muerte asistida comporta riesgos, estos pueden neutralizarse a través de un sistema cuidadosamente diseñado e implementado. Como consecuencia del fallo, el legislador canadiense ha excluido la sanción penal de la muerte asistida bajo ciertas condiciones sustantivas y procedimentales. Se ha optado por un modelo medicalizado para adultos capaces que padecen una grave e irremediable enfermedad; es decir, se encuentran en un avanzado estado de irreversible disminución de su capacidad, sufren un duradero e intolerable padecimiento físico o psicológico que no puede ser aliviado en condiciones que consideran aceptables y su muerte es razonablemente previsible, aunque no es necesario realizar un pronóstico aproximado del período que les resta de vida. 
derecho fundamental se limita a negarles su amparo, pero en ningún caso las rechaza ${ }^{50}$.

Tampoco significa que no exista relación entre el derecho a la vida y la capacidad para disponer de ella. Al contrario, cualquier intento de regularla sí estará condicionado por el deber que el derecho impone al Estado de proteger la vida de sus ciudadanos, especialmente si es ejecutada con la ayuda del poder público o de un tercero. En este sentido, no podemos olvidar que, como se desprende del case law del TEDH y de las dos jurisdicciones constitucionales que han legalizado en ciertas circunstancias la muerte asistida (Colombia y Canadá), hoy en día el objeto de debate ya no son tanto las acciones personales e íntimas de disposición, sino precisamente la posibilidad de demandar asistencia de mayor o menor grado para ejecutarlas.

En definitiva, afirmar que el derecho a la vida no comprende el derecho a disponer de la vida propia no autoriza a una interpretación sensu contrario que rechace esa facultad. Tan solo se limita a reconocer que ese acomodo constitucional no es posible. Pero ello tampoco quiere decir que su eventual regulación pudiera sustraerse a lo que dicho derecho impone; por la misma razón que estaría sujeta al resto de preceptos constitucionales.

Es cierto, sin embargo, que esta conclusión es problemática atendida la literalidad de la doctrina del Tribunal Constitucional espańol y que ha estado sujeta a evolución en el caso del Tribunal Europeo de Derechos Humanos.

Aunque en sentido estricto, y a diferencia del TEDH, el TC nunca ha abordado frontalmente el anclaje constitucional de la libre disposición de la vida propia, algunas de sus afirmaciones pondrían en tela de juicio la constitucionalidad de una regulación alternativa a la vigente.

Como se sabe, el Tribunal ha rechazado que el derecho a la vida pueda concebirse como un «derecho de libertad que incluya el derecho a la propia muerte». Disponer de la vida propia sería una mera manifestación de agere licere resultado de que «la vida [es] un bien de la persona que se integra en su círculo de libertad». El problema es que esa conclusión se acompaña del aserto de que en ningún caso puede considerarse un derecho subjetivo $\mathrm{y}$, mucho menos aún, un derecho fundamental que «implique la posibilidad de movilizar el apoyo del poder público», legislador incluido. La razón aducida es que hacerlo significaría «reducir el contenido esencial del derecho ${ }^{51}$ ».

Más allá de la posible contingencia del argumento y de que tal aseveración no se acompaña de argumentación ad hoc, la posición del Tribunal no se

50 Carter c. Canadá (Fiscal General) (2015), $\$ 63$.

51 STC 120/1990/7. Sobre la difícil constitucionalidad de la tipificación del suicidio en sí mismo, véanse, entre otros, Romeo, 1994 y Tomás-Valiente, 1999 y 2003. 
compadece con otras de sus afirmaciones ${ }^{52}$ ni con las tesis del Tribunal Europeo de Derechos Humanos, tal y como vamos a ver.

El TEDH ha perfilado y modulado a lo largo de su doctrina el alcance atribuido al deber de protección de la vida (art. $2 \mathrm{CEDH}$ ), a través de la progresiva inserción del principio de autonomía individual y del encaje de las decisiones sobre el final de la vida propia en el art. $8 \mathrm{CEDH}$.

Así, en un primer momento excluyó radicalmente los actos de participación en el suicidio ajeno del concepto de vida privada del art. 8 del Convenio ${ }^{53}$ y pudo interpretarse que la obligación que tiene el Estado de proteger la vida de las personas se imponía incluso contra su voluntad ${ }^{54}$.

Finalmente, ha entendido que en el contexto de las decisiones al final de la vida el art. $2 \mathrm{CEDH}$ no puede oponerse a la decisión libre y responsable de quien resuelve terminar con su existencia. Por el contrario, la garantía del derecho a la vida obliga al poder público a adoptar mecanismos que garanticen la

52 Por ejemplo, sostener, como se hace en la misma STC 120/1990, que «arrostrar la propia muerte es una manifestación de libertad genérica» devendría problemático. Como se ha puesto de manifiesto, la interpretación literal de esta doctrina «impediría constitucionalmente no sólo la despenalización de la eutanasia voluntaria, sino incluso la relevancia del consentimiento para rechazar tratamientos médicos dirigidos a evitar la muerte» (Ruiz, 2010: 93); facultad, la de rechazar un tratamiento médico, reconocida sin embargo por el propio TC «aun cuando pudiera conducir a un resultado fatal» (STC 37/2011/5).

53 En $R$ c. Reino Unido (1983), cuyo origen está en el recurso interpuesto por un miembro de la organización EXIT condenado por informar y poner en contacto a quienes deseaban poner fin a su vida con quien podía ayudarles a ello, la Comisión afirmó que «ayudar, incitar, aconsejar o procurar el suicidio están excluidos del concepto de privacidad como consecuencia de afectar al interés público en proteger la vida reflejado en la Suicide Act de 1961» (\$13).

54 Así, en Keenan c. Reino Unido (2001) la reclusión y el consiguiente deber de las autoridades en relación con los encarcelados parecen ser utilizados únicamente como criterio para determinar si los poderes públicos «conocían o deberían haber conocido» el riesgo de que la persona se suicidara, hecho que caracterizaría aquel deber como general y, por tanto, independiente de la situación jurídica del titular del derecho; vid., en este sentido, lord Bingham en Pretty c. Fiscal General y Ministro de Interior (Cámara de los Lores [2001], \$8). Algo similar sucedería con la doctrina del TC en el caso de la alimentación forzosa de presos en huelga de hambre: aunque la relación especial de sujeción que une a reclusos y Administración penitenciaria parece esencial en su argumentación, cualquier mención a ella desaparece en sus conclusiones, donde la medida coercitiva se justifica apelando solo a la preservación del «bien» constitucional vida humana. 
libertad absoluta de esa determinación y la protección de los sujetos más vulnerables ${ }^{55}$.

La tajante exclusión de ese tipo de decisiones del ámbito del art. 2 del Convenio no ha impedido incardinarlas en el derecho a la vida privada garantizado por su art. $8^{56}$. En este sentido, su jurisprudencia ha evolucionado desde la afirmación de que no estaba "preparado para descartar que impedir a la demandante poner fin a su vida con la ayuda de un tercero para evitar lo que considera una manera indigna y angustiosa de morir constituye una interferencia en su derecho a la vida privad ${ }^{57}$ » a aseverar expresamente que "el derecho de una persona a decidir cómo y cuándo debería finalizar su vida, siempre y cuando esté en una posición que le permita formar su juicio libremente y actuar en consecuencia, [es] uno de los aspectos protegidos por el derecho a la vida privada ${ }^{58}$.

De esta suerte, la Corte ha examinado desde la legitimidad de la prohibición total de ayudar a otra persona en su muerte y su justificación (Pretty) hasta los eventuales deberes positivos del Estado en relación con el derecho a morir en aquellas jurisdicciones permisivas y los requisitos que pueden establecerse para ser auxiliado en la muerte propia (Haas, Koch y Gross). Y ello en relación con el deseo de morir tanto de personas que padecen una grave enfermedad degenerativa o incurable y que no pueden quitarse la vida por sí mismas (Pretty o Koch) como de quienes sufren una enfermedad mental (Haas) o de quienes, sencillamente, están cansados de vivir (Gross).

55 «El artículo 2 del Convenio [...] obliga a las autoridades nacionales a impedir que una persona pueda quitarse la vida si su decisión no se ha tomado libremente y con plena conciencia de lo que supone [...]. Si un país decide adoptar una posición liberal en este asunto, es necesario que tome medidas de implementación y de prevención adecuadas. Dichas medidas tienen también la finalidad de evitar que organizaciones privadas dedicadas a prestar asistencia en el suicidio actúen ilegalmente o en la clandestinidad con los consiguientes peligros de abuso» (STEDH Haas c. Suiza [2011], $\$ \$ 54$ y 57$)$.

56 «Solo distorsionando el lenguaje podría interpretarse que el artículo 2 del Convenio confiere el derecho diametralmente opuesto, concretamente un derecho a morir; tampoco permite crear un derecho de autodeterminación que otorgue al individuo la capacidad para elegir la muerte en lugar de la vida [...] del artículo 2 del Convenio no puede derivarse un derecho a morir» (STEDH Pretty c. Reino Unido [2002], \$\$ 39 y 40 , antecitada).

57 Ibid., $\$ 67$.

58 SSTEDH Haas c. Suiza (2011), $\$$ 51; Koch c. Alemania (2012), $\$ 52$, y Gross c. Suiza (2013; Sección Segunda), $\$$ 59, donde el Tribunal ha llegado a apelar expresamente al «derecho a poner fin a la vida propia» $(\$ 65)$. 
Esto significa que en el ámbito del Consejo de Europa el debate ya no es si existe o no un derecho a disponer de la vida, sino cómo y con qué límites puede reconocerse y regularse en el marco del Convenio ${ }^{59}$. Es cierto que en la inmensa mayoría de Estados, y probablemente como consecuencia de evaluar su capacidad para neutralizar totalmente los riesgos inherentes a una regulación permisiva, el deber que impone el art. $2 \mathrm{CEDH}$ se habría traducido en la prohibición absoluta de participar en la muerte de un tercero $^{60}$.

La doctrina del TEDH suscita múltiples incógnitas de entre las que destacan especialmente dos: la naturaleza de ese «derecho a decidir cómo y cuándo» terminar con la vida de uno y la creo que inocultable preferencia del Tribunal por la despenalización de la muerte asistida.

Comenzando por la primera, conviene recordar que, a pesar del carácter expansivo y plural del derecho a la vida privada y familiar y de la confusión que pueden provocar algunas de sus afirmaciones, el art. $8 \mathrm{CEDH}$ ampara esencialmente un espacio de libertad individual libre de intrusiones ilegítimas del poder público ${ }^{61}$. En otras palabras, delimita un espacio que protege decisiones que en sí mismas no son objeto de garantía, algo solo predicable de la prohibición de intromisión injustificada en los términos del Convenio $^{62}$.

No obstante, la voluntad de disponer de la vida propia parece trascender esta naturaleza y se le adosa una importante vertiente prestacional. Ello ha permitido al Tribunal, por ejemplo, someter a escrutinio las circunstancias en las que una jurisdicción tolerante con la muerte asistida permite el acceso a las sustancias que posibilitan un suicidio seguro e indoloro. Pero, y aquí está la clave, no tanto desde la óptica de los deberes que impone el art. 2 del Convenio, sino

59 En este sentido, Dorscheidt, 2012: 188.

60 Como afirma el Tribunal en un razonamiento no exento de contradicciones a la luz de su contexto, «la inmensa mayoría de los Estados otorgan más peso a la protección de la vida del individuo que a su derecho a terminarla» (STEDH Haas c. Suiza [2011], \$55).

61 «Este Tribunal reitera además que la finalidad esencial del artículo 8 del Convenio es proteger a la persona frente a intromisiones arbitrarias del poder público. Cualquier injerencia en lo garantizado por su párrafo primero, deberá estar justificada con arreglo a lo establecido en su párrafo segundo» (STEDH Gross c. Suiza [2013; Sección Segunda], \$ 61).

62 Sin embargo, la doctrina del consentimiento informado al amparo del derecho a la integridad personal, que el Tribunal también ha ubicado en el art. $8 \mathrm{CEDH}$, posee los perfiles propios de una concepción que podríamos denominar de «derecho fundamental fuerte». 
sobre todo desde el prisma de su art. 8.263. No se olvide que en caso de adoptar una postura «liberal» en esta materia, el poder público no solo habría de establecer medidas preventivas, sino también de implementación con la doble finalidad de posibilitar la decisión de morir y de evitar los peligros de abuso. Algo especialmente importante cuando son organizaciones privadas las que prestan asistencia al suicidio ${ }^{64}$.

Pero ello significa transitar desde una facultad personal inicialmente protegida de la injerencia del poder público (decidir cómo y cuándo poner fin a la vida propia) al derecho a obtener permiso o ayuda en mayor o menor grado del Estado con arreglo a un estricto marco regulativo para realizar ese acto dispositivo ${ }^{65}$. Y sin que, además, todas las cautelas que habitualmente se adoptan puedan explicarse recurriendo a los deberes que impone el art. $2 \mathrm{CEDH}$.

Este último es un problema clásico: cómo afrontar la aparente inconsistencia de que una capacidad atribuida en principio a toda persona con independencia de sus circunstancias personales es, sin embargo, regulada, allí donde se ha optado por legalizarla, fundamentalmente en atención a su condición clínica ${ }^{66}$. Una cuestión que, probablemente, tenga que ver con la legí-

63 El TEDH asevera en Haas que «la solicitud del demandante de obtener sin prescripción médica una dosis de pentobarbital sódico debe examinarse desde la perspectiva del deber positivo del Estado de adoptar las medidas necesarias en orden a permitir un suicidio digno" (STEDH Haas c. Suiza [2011], \$ 53); examen que concluye confirmando la legitimidad de la exigencia de prescripción médica a la luz del art. 8.2 CEDH.

$64 \quad$ Ibid., $\$$ 57. En torno a las diferencias entre un modelo medicalizado y desmedicalizado de muerte asistida, vid. Delbeke, 2011.

65 La cuestión aún no se ha suscitado en toda su crudeza, pues de momento el Tribunal solo ha resuelto peticiones para que no se castigara penalmente a quienes asistieran en la muerte de otro y para acceder a una sustancia que permita un suicidio seguro.

66 Recientemente en la doctrina española, Tomás-Valiente (2016: 68-69). Ningún sistema, ni siquiera el más permisivo, reconoce un derecho general a disponer de la vida propia. Por el contrario, se procede a despenalizar de forma más o menos amplia la muerte asistida siempre que concurran una serie de circunstancias referidas a la situación clínica del individuo y se respeten unos protocolos de actuación; sobre las distintas maneras que tienen los ordenamientos de regular las decisiones sobre el final de la vida, vid. Casonato, 2011. Como afirma Tannsjo, el problema además radica en explicar las opciones adoptadas de un modo no ad hoc (Tannsjo, 2015), algo especialmente difícil en una materia caracterizada no pocas veces por lo dramático de las situaciones personales y los sentimientos que despiertan (Warnock y Macdonald, 2008: 10; o Barbisan, 2016: 84). 
tima libertad reguladora de un Estado del que se solicita que permita o posibilite una determinada prestación, cuando no se le demanda que la proporcione directamente a través de su sistema público de salud.

En segundo lugar, aunque el derecho a la vida privada es propicio para conllevar las notables diferencias con las que los países integrantes del Consejo de Europa abordan la regulación de las «decisiones sobre el final de la vida», es perceptible cierta predilección del Tribunal por un futuro escenario de regulación de la muerte asistida.

Esta inclinación se manifiesta, por ejemplo, cuando interpreta como «falta de consenso» que solo cuatro de los 42 miembros del Consejo de Europa la hayan legalizado (Haas y Koch ${ }^{67}$; cuando salva la legitimidad de la prohibición absoluta de la asistencia al suicidio porque puede ser flexibilizada en virtud de las circunstancias concurrentes hasta el punto de que no se inicien acciones penales (Pretty), o, más problemáticamente, cuando el margen de apreciación parece transformarse en un juicio de las autoridades estatales acerca de su capacidad para neutralizar los riesgos de legalización de la muerte asistida y cumplir así con lo que impone el art. $2 \mathrm{CEDH}^{68}$.

67 Parece difícil hablar de falta de consenso en una situación de aproximadamente nueve a uno en favor de una opción.

68 Esta predilección es palmaria en Gross c. Suiza (2013; Sección Segunda), donde la Corte interpreta como incertidumbre lesiva del derecho a la vida privada que los médicos suizos solo puedan prescribir una dosis letal de pentobarbital sódico a los enfermos terminales. Así, en lugar de constatar que con arreglo a la práctica consolidada en Suiza la demandante no tenía derecho a que se le prescribiera la sustancia, el Tribunal concluye que existe una imprevisión que vulnera su derecho a la vida privada y conmina a las autoridades a remediarla. Los votos particulares de los magistrados Raimondi, Jociene y Karakas ahondan en esta cuestión: en Suiza existen unas reglas que son legítimas a la luz de la doctrina sentada en Haas y la demandante sencillamente no las cumplía.

Esta problemática sentencia fue finalmente anulada por la Gran Cámara el 30 de septiembre de 2014 si bien no por motivos de fondo. El 12 de agosto de 2013 el Gobierno suizo solicitó que el asunto fuera remitido a ella en aplicación del art. 43 $\mathrm{CEDH}$. Durante el procedimiento se descubrió que la demandante había fallecido el 10 de noviembre de 2011, es decir, año y medio antes de que la Sección Segunda fallara, con la ayuda de EXIT y tras encontrar un médico que le recetó la dosis de pentobarbital. Esta circunstancia se mantuvo sin embargo oculta con la intención de que no se paralizara el proceso. Ante estos hechos, la Gran Cámara estimó la objeción planteada por el Gobierno suizo y declaró inadmisible la demanda, pues la conducta de la reclamante constituyó un abuso de derecho con arreglo a lo dispuesto en el art. 35.3.a) $\mathrm{CEDH}$. 


\section{REFLEXIONES FINALES}

Como ha tratado de mostrarse, un hipotético derecho a disponer de la vida propia es extraño al derecho fundamental a la vida. Además, el debate no tiene tanto que ver con esa facultad, cuanto con un eventual derecho a ser asistido en la muerte en mayor o menor grado, incluso por el poder público. Una discusión compleja que obliga a afrontar simultáneamente distintos tipos de problemas y donde la garantía del derecho a la vida no puede ser postergada, pues impone ciertas cautelas.

Quizá nos hallemos próximos a un impasse. Una especie de tierra de nadie entre una prohibición absoluta de la muerte asistida que arriesga su inadecuación constitucional y una ausencia de apoyo constitucional expreso, pero no un rechazo, a un derecho a disponer de la vida propia. En otras palabras, un escenario de dudosa constitucionalidad de la blanket prohibition de la ayuda a morir que, sin embargo, no derivaría de la existencia de un derecho constitucional específico.

Tal vez asistamos al nacimiento de un derecho de nuevo cuńo que puede rastrearse fragmentariamente en valores, principios y derechos pero que, como tal, no encuentra acomodo exclusivo en ninguno.

Y ello en un contexto en el que limitadamente ya se permiten ciertos actos de libre disposición de la vida y nuestra sociedad ha experimentado un permanente y sólido cambio en favor de una reconsideración del actual cuerpo legal ${ }^{69}$.

No debe ocultarse que se trata de una situación jurídica especialmente delicada: una coyuntura en la que difícilmente el poder público puede oponerse a actos de libre disposición de la vida propia (Chueca, 2009) y donde la clave radica, en aquellos países más avanzados, sobre todo con sistemas de salud públicos universales, en que se trata de una prestación que se demanda en mayor o menor medida del Estado.

Esta situación solo puede agravarse y tornarse más incierta si no es afrontada por el legislador democrático y se deja en manos de los órganos jurisdiccionales ${ }^{70}$.

69 El 84\% de los encuestados respondió afirmativamente a la siguiente pregunta realizada por Metroscopia a finales de febrero de 2017: «¿Debería tener derecho un enfermo incurable a que los médicos le proporcionaran algún producto para poner fin a su vida sin dolor?». Un dato que evidenciaría un claro apoyo de carácter transversal; vid. https://bit.ly/2noPfIm (última consulta 19 de marzo de 2019).

70 Para el caso canadiense, vid., por ejemplo, Chan y Sommerville, 2016. Han sido muchos quienes, incluso desde las propias instancias judiciales, han defendido la 
Y puede llegar a ser crítica si, en un futuro no imaginario, el TEDH diera un giro «à la Carter» $\mathrm{y}$ juzgara que $y a$ concurren las circunstancias que permiten neutralizar los riesgos que conlleva legalizar la muerte asistida.

\section{Bibliografía}

Barbisan, B. (2016). Law and "the right to die»: Filling a reservoir with an eye-dropper. BioLaw, 3, 81-92. Disponible en: http://dx.doi.org/10.15168/blj.v0i3.

Barcelona Llop, J. (2007). La garantía europea del derecho a la vida y a la integridad personal frente a la acción de las fuerzas del orden. Cizur Menor: Thomson-Civitas.

Beltrán Aguirre, J. L. (2010). El derecho de las personas a una muerte digna. Aranzadi Doctrinal, 5, 83-96.

Casonato, C. (2011). Informed consent and end of life decisions: notes of comparative Law. Maastricht Journal of European Comparative Law, 18 (3), 225-256. Disponible en: https://doi.org/10.1177/1023263X1101800302.

Chan, B. y Sommerville, M. (2016). Converting the «right to life» to the «right to physician-assisted suicide and euthanasia»: an analysis of Carter $v$ Canada (Attorney General), Supreme Court of Canada. Medical Law Review, 24 (2), 143-175. Disponible en: https://doi.org/10.1093/medlaw/fww005.

Chueca Rodríguez, R. (2009). El marco constitucional del final de la propia vida. Revista Española de Derecho Constitucional, 85, 99-123.

(2017). End of life issues (en prensa; consultado por cortesía del autor).

Delbeke, E. (2011). The Way Assisted Suicide is legalised: balancing a medical framework against a demedicalised model. European Journal of Health Law, 18 (2), 149-162. Disponible en: https://doi.org/10.1163/157180911X565191.

necesidad de afrontar legislativamente el problema: «En nuestra democracia parlamentaria, y entiendo que también en numerosos Estados del Consejo de Europa, un cambio tan trascendental no puede provenir de la creatividad judicial. Por el contrario, requiere de una detallada y efectiva propuesta regulativa. En estas condiciones, no alcanzo a ver cómo el proceso de interpretación de los derechos garantizado por el Convenio podría alumbrar un resultado que incorporara todas las cautelas necesarias. Básicamente, este es un asunto que debe ser objeto de un debate democrático y que debe ser decidido por el poder legislativo», Lord Stein en Pretty, $\$$ 57, antecitada. Sin embargo, el poder público suele ser reacio a regular estas cuestiones por temor a las consecuencias políticas y no suele intervenir hasta que se ve compelido a ello (Summer, 2011: 210). Esta circunstancia ha conducido a que en numerosas jurisdicciones exista una abundantísima jurisprudencia sobre todo tipo de decisiones relativas al final de la vida; pero la naturaleza de estos dilemas nos sitúa ante el peligro cierto de que los órganos jurisdiccionales se comporten como meros «árbitros morales» (Samanta, 2016: 2). 
Dickson, B. (2013). Human Rights and the United Kingdom Supreme Court. Oxford Scholarship Online. Disponible en: https://doi.org/10.1093/acprof:oso/9780199697458.001.0001.

Dorscheidt, J. (2012). Euthanasia and physician-assisted suicide from a human rights perspective. En B. Toebes et al. (eds.). Health and Human Rights in Europe (pp. 177-210). Antwerp: Intersentia.

Glover, J. (1977). Causing Death and Saving Lives. London: Penguin.

Griffin, J. (2008). On Human Rights. Oxford Scholarship Online. Disponible en: https://doi. org/10.1093/acprof:oso/9780199238781.001.0001.

Harrington, J. (2014). Access to essential medicines in Kenya: intellectual property, anti-Counterfeiting and the right to health. Law and Global Health. Current Legal Issues, 16, 180201. Disponible en: https://doi.org/10.1093/acprof:oso/9780199688999.003.0007.

Inbadas, H., Zaman, S., Whitelaw, S. y Clark, D. (2017). Declarations on euthanasia and assisted dying. Death Studies. Disponible en: https://doi.org/10.1080/07481.2017.1317300.

Jasanoff, S. (2011). Introduction: rewriting life, reframing rights. En S. Jasanoff (ed.). Reframing Rights: Bioconstitutionalism in the Genetic Age (pp. 1-28). Cambridge: The MIT Press.

Korff, D. (2006). The right to life. A guide to the implementation of Article 2 of the European Convention on Human Rights. Strasbourg: Consejo de Europa.

Loveland, K. (2016). Death and its dignities. New York University Law Review, 91, 1279-1315.

Mavronicola, N. (2017). Taking Life and Liberty Seriously: Reconsidering Criminal Liability Under Article 2 of the ECHR. The Modern Law Review, 80 (6), 1026-1051.

McLean, S. (2007). Assisted dying: reflections on the need for Law reform. Oxon: Routledge-Cavendish.

Muders, S. (ed.) (2017). Human dignity and assisted death. Oxford Scholarship Online. Disponible en: https://doi.org/10.1093/oso/9780190675967.001.0001.

Pabst Battin, M. (2005). Ending Life: Ethics and the Way We Die. New York: Oxford University Press.

Prokopetz, J. y Soleymani, L. (2012). Redefining Physician's Role in Assisted Dying. New England Journal of Medicine, 367, 97-99. Disponible en: https://doi.org/10.1056/ NEJMp1205283.

Rey Martínez, F. (2008). Eutanasia y derechos fundamentales. Madrid: Centro de Estudios Políticos y Constitucionales.

(2009). La protección jurídica de la vida ante el Tribunal de Estrasburgo: un derecho en expansión y transformación. Estudios Constitucionales, 1, 331-360. Disponible en: http://dx.doi.org/10.4067/S0718-52002009000100011 2009.

Romeo Casabona, C. M. (1994). El derecho y la bioética ante los límites de la vida humana. Madrid: Editorial Centro de Estudios Ramón Areces.

Rose, N. (2010). The value of life: somatic ethics and the spirit of biocapital. En J. Yorke (ed.). The Right to Life and the Value of Life (pp. 85-100). Burlington: Ashgate.

Ruiz Miguel, A. (2010). Autonomía individual y derecho a la propia muerte. Revista Española de Derecho Constitucional, 89, 11-43.

Samanta, J. (2016). Enforcing Human Rights at End of Life: Is There a Better Approach? En A. Diver y J. Miller (eds.). Justiciability of Human Rights Law in Domestic Jurisdictions (pp. 1-23). Springer. Disponible en: https://doi.org/10.1007/978-3-319-24016-9_1. 
Schabas, W. A. (2002). The Abolition of the Death Penalty in International Law. Cambridge: Cambridge University Press.

Simón Llorda, P. et al. (2008) Ética y muerte digna: propuesta de consenso sobre un uso correcto de las palabras. Revista Calidad Asistencial, 23 (6), 271-285. Disponible en: https://doi.org/10.1016/S1134-282X(08)75035-8.

Skegg, P. D. G. (1988). The edges of life. Otago Law Review, 6 (4), 517-532.

Summer, L. W. (2011). Assisted Death: A Study in Ethics and Law. Oxford Scholarship Online. Disponible en: https://doi.org/10.1093/acprof:oso/9780199607983.001.0001.

Tannsjo, T. (2015), Taking Life: Three Theories on the Ethics of Killing. Oxford Scholarship Online. Disponible en: https://doi.org/10.1093/acprof:oso/9780190225575.001.0001.

Toebes, B., Hartlev, M., Hendriks, A. y Herrmann, J. R. (eds.) (2012). Health and Human Rights in Europe. Antwerpen: Intersentia.

Tomás-Valiente, C. (1999). La disponibilidad de la propia vida en el derecho penal. Madrid: Centro de Estudios Políticos y Constitucionales.

— (2003). La disponibilidad de la propia vida: aspectos constitucionales. En El derecho a la vida. Madrid: Tribunal Constitucional; Centro de Estudios Políticos y Constitucionales.

- (2016). La eutanasia: marco legal en España y encaje del posible derecho a disponer de la propia vida. En Eutanasia y suicidio asistido. Barcelona: Fundación Griffols. Disponible en: https://bit.ly/2GKmGBf.

Veatch, R. M. (1999). The Conscience Clause: How much Individual Choice in Defining Death can our Society Tolerate? En S. J. Younger, R. M. Arnold y R. Schapiro (eds.) The Definition of Death: Contemporary Controversies (pp. 137-160). Baltimore: Johns Hopkins University Press.

Warnock, M. y Macdonald, E. (2008). Easeful death. Is there a case for assisted dying? Oxford: Oxford University Press.

Wicks, E. (2010). The right to life and conflicting interests. Oxford Scholarship Online. Disponible en: https://doi.org/10.1093/acprof:oso/9780199547395.001.0001.

- (2012). The Meaning of «Life»: Dignity and the Right to Life in International Human Rights Treaties. Human Rights Law Review, 12 (2), 199-219. Disponible en: https://doi. org $/ 10.1093 /$ hrlr/ngs002.

Yorke, J. (2010). Introduction: The Right to Life and the Value of Life: Orientations in Law, Politics and Ethics. En J. Yorke (ed.). The Right to Life and the Value of Life (pp. 1-36). Burlington: Ashgate.

Zucca, L. (2007), Constitutional dilemmas. Oxford Scholarship Online. Disponible en: https://doi.org/10.1093/acprof:oso/9780199552184.001.0001. 